\title{
Monatomic Iodine Dielectric Layer for Multimodal Optical Spectroscopy of Dye Molecules on Metal Surfaces
}

Yasuyuki Yokota,,${ }^{1,2, *}$ Raymond A. Wong, ${ }^{1}$ Misun Hong, ${ }^{1}$ Norihiko Hayazawa, ${ }^{1}$ Yousoo Kim ${ }^{1, *}$

${ }^{1}$ Surface and Interface Science Laboratory, RIKEN, 2-1 Hirosawa, Wako, Saitama 351-0198, Japan

${ }^{2}$ JST PRESTO, 4-1-8 Honcho, Kawaguchi, Saitama 332-0012, Japan

- Calculation of Vibrational Spectra

- Figure S1: Details of emission spectra of MgPc film on glass

- Figure S2: Full XPS spectra of $\mathrm{MgPc} / \mathrm{I}-\mathrm{Au}(111)$ and $\mathrm{MgPc} / \mathrm{Au}(111)$

- Figure S3: UPS spectra of $\mathrm{MgPc} / \mathrm{I}-\mathrm{Au}(111)$ and $\mathrm{MgPc} / \mathrm{Au}(111)$

- Figure S4: Details of STM image of $\mathrm{MgPc} / \mathrm{Au}(111)$

- Figure S5: Emission spectra of $\mathrm{MgPc} /$ roughened $\mathrm{Au}$ and $\mathrm{MgPc} / \mathrm{I}-$ roughened $\mathrm{Au}$

- Figure S6: Emission spectra of $\mathrm{MgPc} / \mathrm{CnSH}-\mathrm{Au}(111)$ and comparison of fluorescent components

- Figure S7: Molecular orbitals and characteristic vibration modes of MgPc and NB

- Figure S8: First overtone and combination Raman bands of MgPc/I-Au(111)

- Figure S9: Absorption and emission spectra of $\mathrm{ZnPc}$ solution and $\mathrm{ZnPc} / \mathrm{I}-\mathrm{Au}(111)$

\section{Calculation of Vibrational Spectra}

The optimized structures and vibrational spectra of the $\mathrm{MgPc}$ and NB molecules were calculated using Gaussian $16 .{ }^{\mathrm{S}}$ Density functional theory (DFT) calculations using the B3LYP hybrid functional with the 6-31G(d) basis set were performed to optimize the structure under the $\mathrm{D}_{4 \mathrm{~h}}$ symmetry as outlined in previous studies ${ }^{\mathrm{S} 2}$ and the vibrational frequencies were obtained. The resonance Raman spectra were calculated by the default procedure implemented in Gaussian $16,{ }^{\mathrm{S} 3-\mathrm{S} 4}$ and convoluted using Lorentzian broadening, with full width at half maximum (FWHM) of $16 \mathrm{~cm}^{-1}$. The wavenumbers were scaled by a factor of 0.96 to correct for anharmonicity effects. 


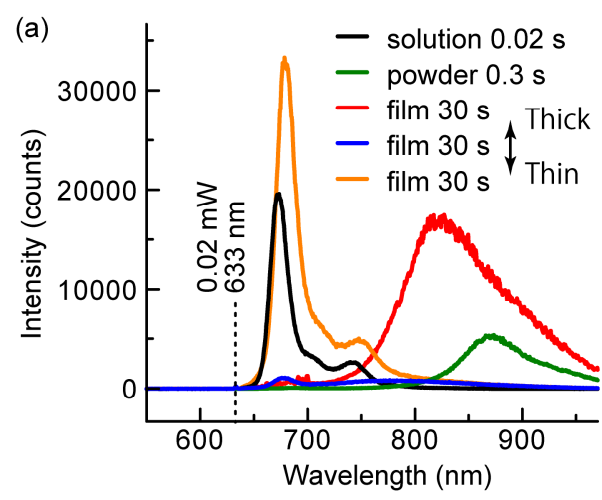

(b)

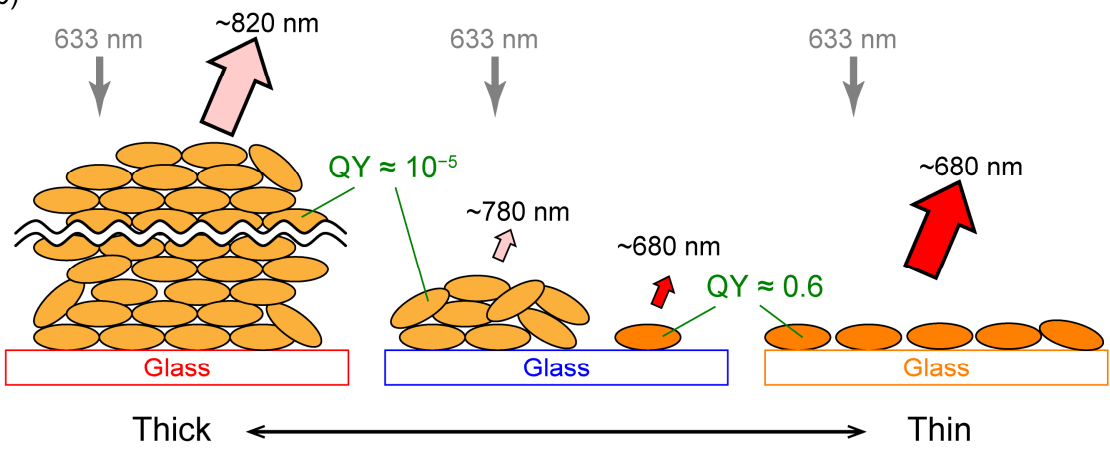

Figure S1. (a) Emission spectra of various MgPc samples before normalization; (black) $0.01 \mathrm{mM} \mathrm{MgPc}$ acetone solution, (green) MgPc powder, and (red)(blue)(orange) MgPc film with different thicknesses deposited on a glass slide. Exposure time is indicated in the figure. Normalized spectra are shown in Figure 2(a). (b) Schematic of the emission measurements of MgPc film in (a). The values of quantum yield (QY) are from Ref. S5. Note that the magnitude of the shot noise increases according to the square root of the intensity of light, thus the longer wavelength side of the red spectrum in (a) appears to have more noise.
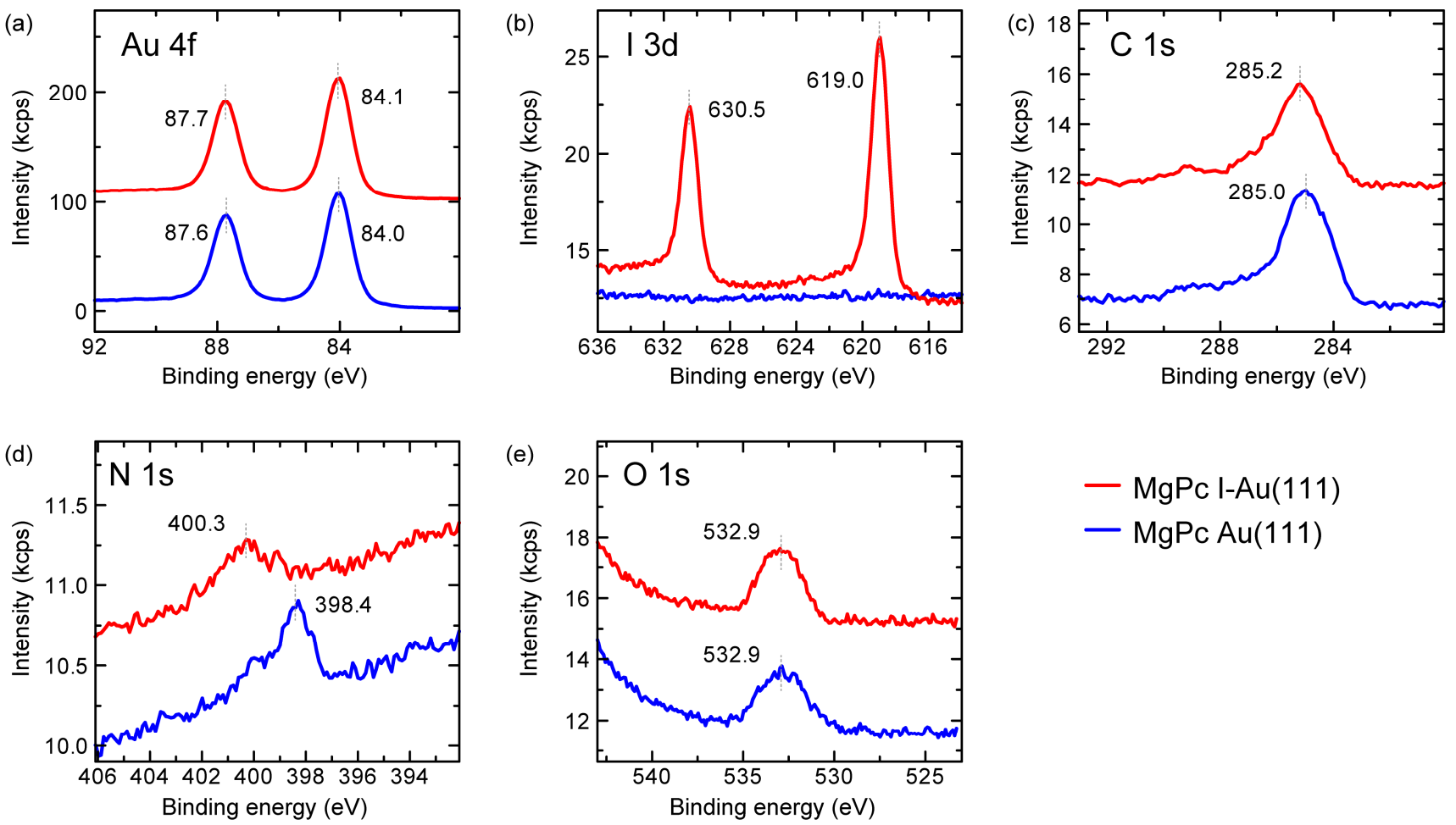

Figure S2. XPS spectra of (red) I-Au(111) and (blue) Au(111) substrates after the deposition of MgPc molecules; (a) Au 4f, (b) I 3d, (c) C 1s, (d) N 1s, and (e) O 1s. Note that the appearance of the O 1s peak in both samples indicates the presence of molecules coordinated to MgPc (e.g. water and acetone) and/or small amount of contamination deposited during the sample transfer. 

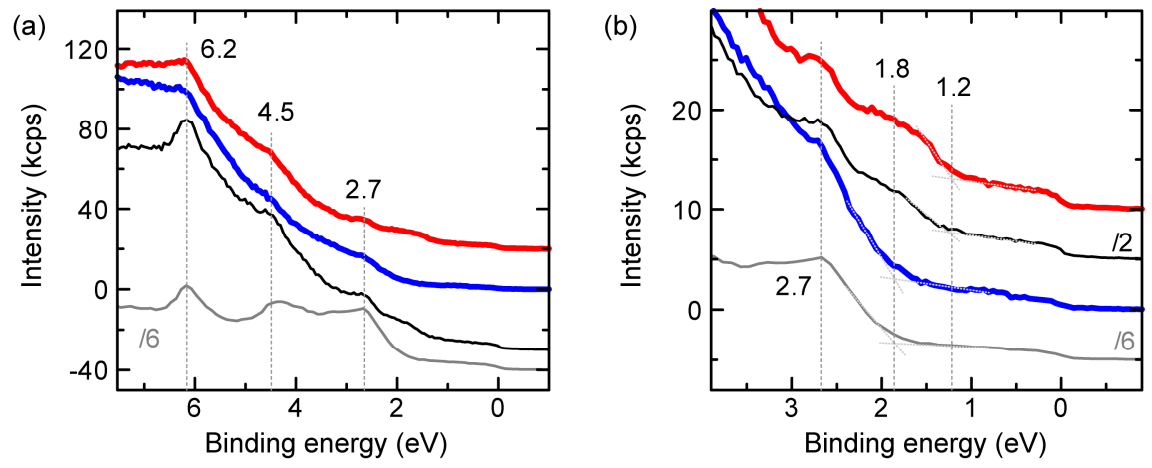

- MgPc I-Au(111)

- $\operatorname{MgPc} A u(111)$

- I-Au(111)

- clean Au

Figure S3. (a) UPS spectra of (red) I-Au(111) and (blue) $\mathrm{Au}(111)$ substrates after the deposition of MgPc molecules with the reference spectra of I-Au(111) and clean Au. (b) Magnified spectra of (a) near the Fermi energy. Characteristic features observed at 2.7, 4.5, and $6.2 \mathrm{eV}$ in all spectra are derived from $\mathrm{Au} 5 \mathrm{~d}$ states and indicate that the $\mathrm{MgPc}$ layer as well as the iodine layer is significantly thin to detect the photoelectron from the Au substrate. Note that the apparent absence of the HOMO peak of MgPc molecules indicate the various adsorption states which render it difficult to distinguish the signal from the background.
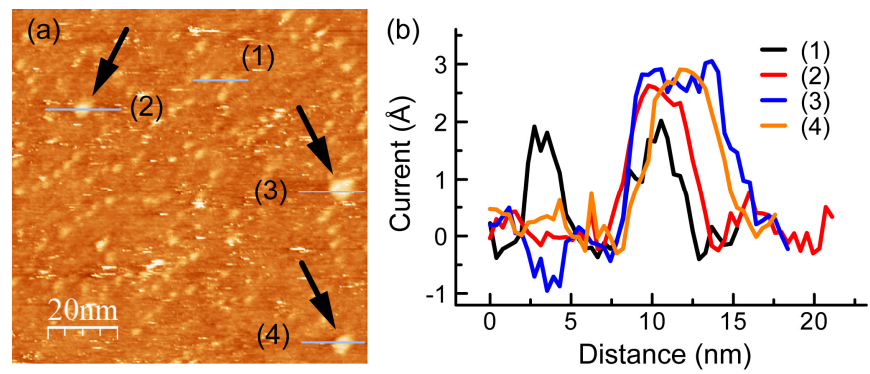

Figure S4. (a) STM image of $\mathrm{MgPc} / \mathrm{Au}(111)$ taken in air and (b) height profiles indicated in (a). The common island height of $\sim 2.6 \AA$ suggests that the islands marked with arrows in (a) are likely to contain Au islands, while islands like (1), which are small in size, are more likely to be adsorbed molecules and/or weakly interacted aggregates. 
(a)

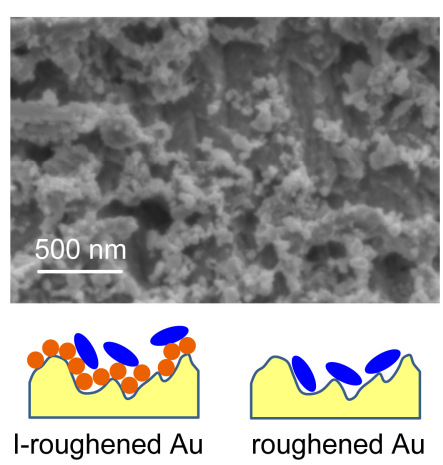

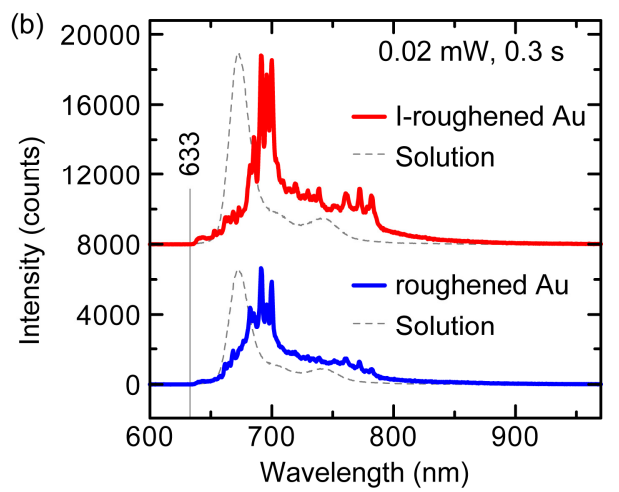

Figure S5. (a) A typical SEM image of electrochemically-roughened Au. Possible adsorption structures of MgPc molecules are drawn at the bottom. (b) Emission spectra of MgPc molecules deposited on electrochemically-roughened $\mathrm{Au}$ (red) with and (blue) without iodine modification. Dashed lines indicate the emission spectra of $0.01 \mathrm{mM} \mathrm{MgPc}$ solution for comparison.

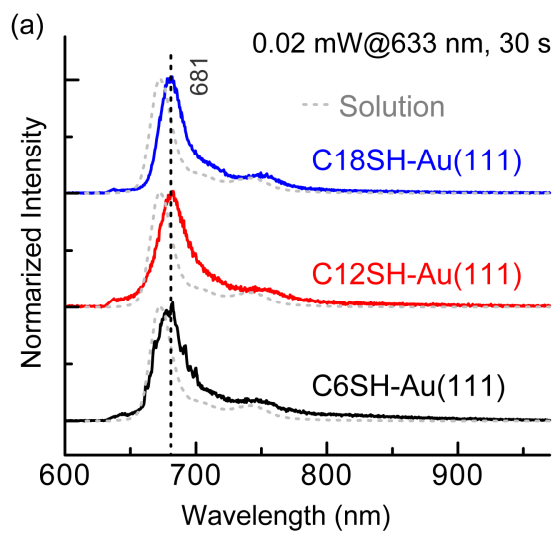

(c)

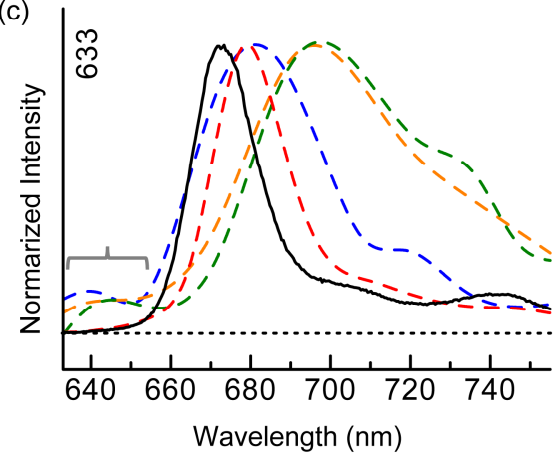

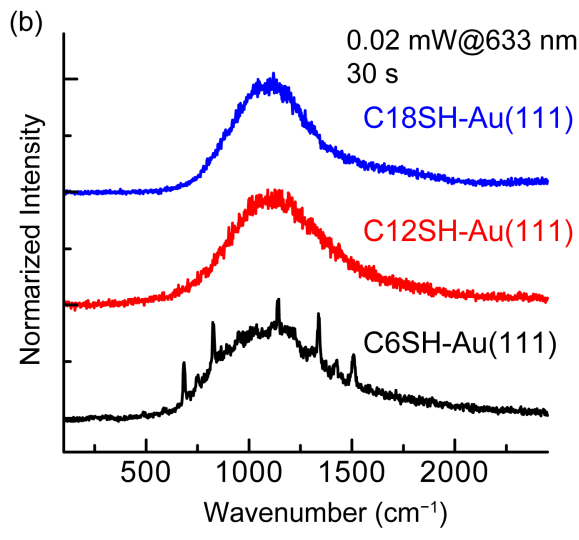

Solution

$\lambda_{\max }=673 \mathrm{~nm}$

Glass

$\lambda_{\max }=679 \mathrm{~nm}$

C6SH-Au(111)

$\lambda_{\max }=681 \mathrm{~nm}$

I-roughened Au

$\lambda_{\max }=694 \mathrm{~nm}$

I-Au(111)

$\lambda_{\max }=697 \mathrm{~nm}$

Figure S6. (a)(b) Emission spectra of MgPc molecules deposited on C6SH-Au(111), C12SH-Au(111), and C18SH-Au(111). Spectra were obtained with (a) 150 and (b) 600 grooves $/ \mathrm{mm}$. Emission spectra of $0.01 \mathrm{mM} \mathrm{MgPc}$ solution are also shown in (a) for comparison. Sample preparations for $\mathrm{C} 12 \mathrm{SH}-\mathrm{Au}(111)$ and $\mathrm{C} 18 \mathrm{SH}-\mathrm{Au}(111)$ are almost identical to $\mathrm{C} 6 \mathrm{SH}-\mathrm{Au}(111)$. Absence of resonance Raman peaks are evident for $\mathrm{C} 12 \mathrm{SH}-\mathrm{Au}(111)$ and $\mathrm{C} 18 \mathrm{SH}-\mathrm{Au}(111)$. In addition, while the peak shape of the fluorescence of $\mathrm{C} 6 \mathrm{SH}-\mathrm{Au}(111)$ is slightly distorted, the shapes of the $\mathrm{C} 12 \mathrm{SH}-\mathrm{Au}(111)$ and $\mathrm{C} 18 \mathrm{SH}-\mathrm{Au}(111)$ are closer to that of a thin $\mathrm{MgPc}$ film on the glass substrate (Figure 2(a)). (c) Fluorescence spectra of various MgPc samples extracted from Figure 5(a). The shortest wavelength regions indicated by parenthesis may include the residual signal originated from the emission of $\mathrm{Au}$ substrates. 
(a)

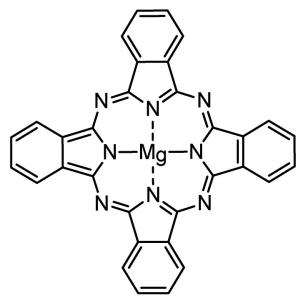

MgPc

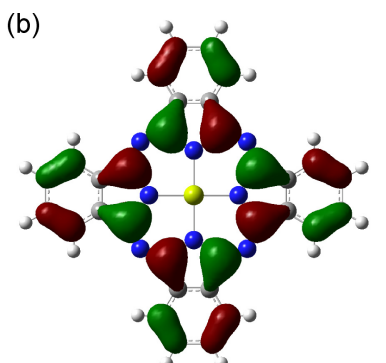

HоMо
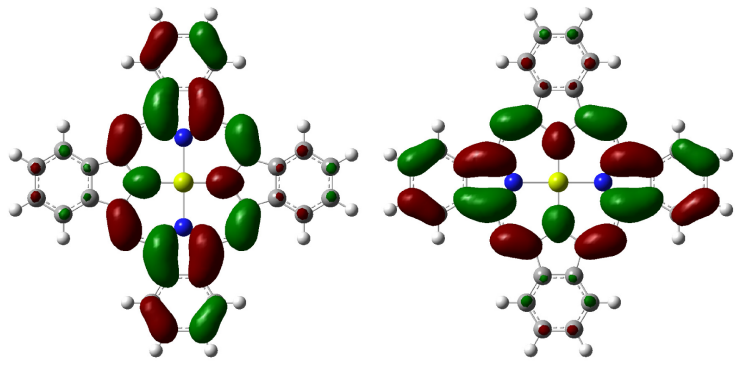

LUMOs

(c)
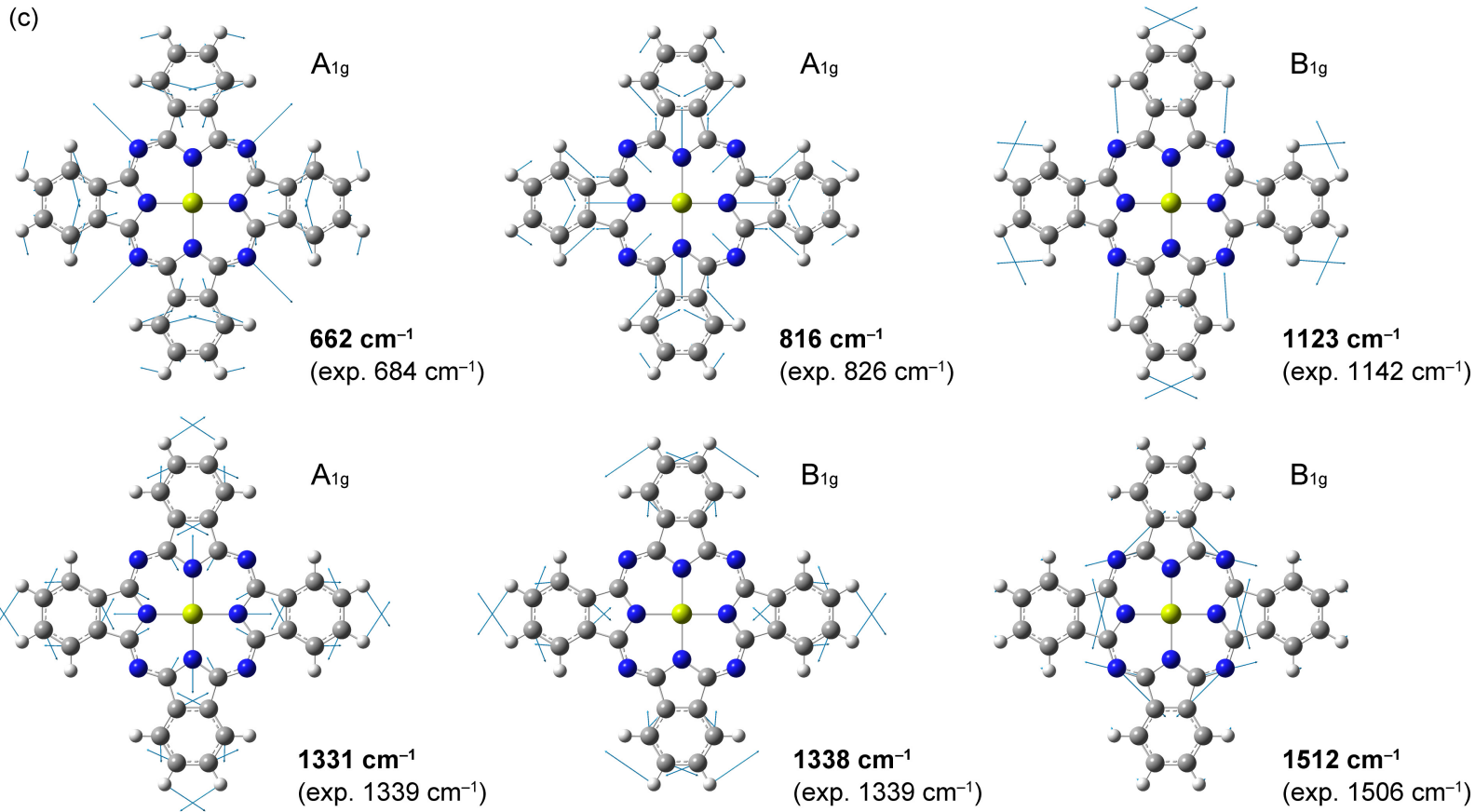

(d)<smiles></smiles>

NB (e)

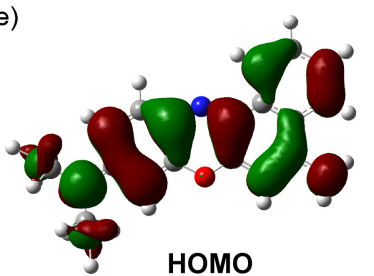

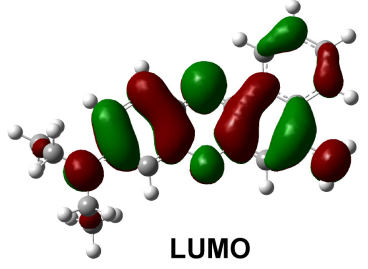

(f)

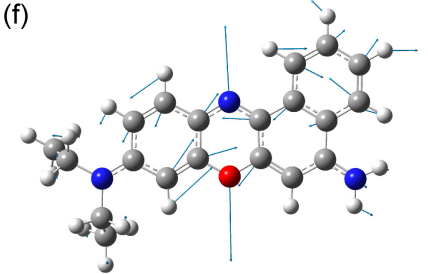

istob-0000000$\log _{32} 0$

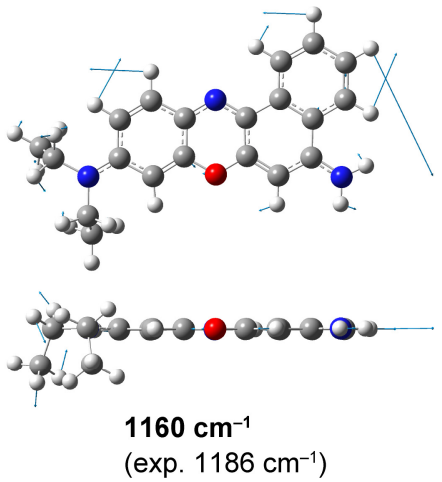

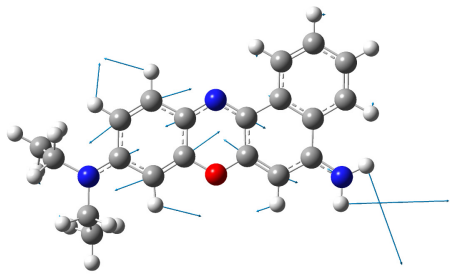

280000000000 $-g_{20} a_{0}$

$1625 \mathrm{~cm}^{-1}$

(exp. $1645 \mathrm{~cm}^{-1}$ )

Figure S7. (a) Molecular structure of MgPc and (b) molecular orbitals that primarily contribute to absorption and fluorescence. (c) Characteristic vibration modes of MgPc whose energy is displayed in Figure 5(b). (d) Molecular structure of NB and (e) molecular orbitals that primarily contribute to absorption and fluorescence. (f) Characteristic vibration modes of NB whose energy is displayed in Figure 6(e). Molecular orbitals and vibration modes are displayed using Gauss View software. ${ }^{\mathrm{S} 6}$ 


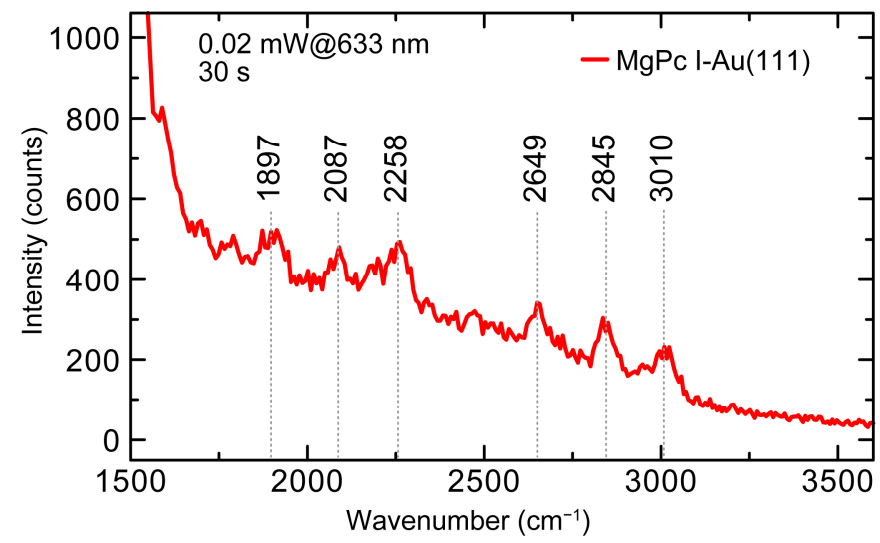

1897

1890: $748+1142$

2087

2087: $748+1339$

2258

2254: $748+1506$

2649

2648: 1142 + 1506

2845

2845: $1339+1506$

3010

3012: $1506+1506$

Figure S8. (a) Resonance Raman spectrum of MgPc molecules deposited on the I-Au(111) substrate at high wavenumber regions. Plausible fundamental components giving rise to the first overtone and combination Raman bands are shown at the right side. The band at $748 \mathrm{~cm}^{-1}$ is observed between 684 and $826 \mathrm{~cm}^{-1}$ in Figure 5(b) (see also Figure S9(c)) and is attributed to $B_{1 g}$ mode.

(a)

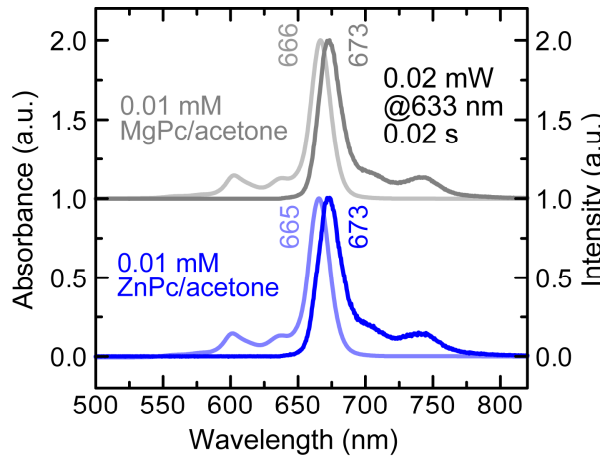

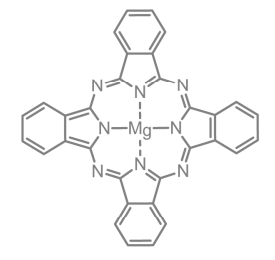

$\mathrm{MgPc}$

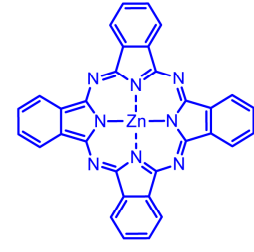

$\mathrm{ZnPc}$
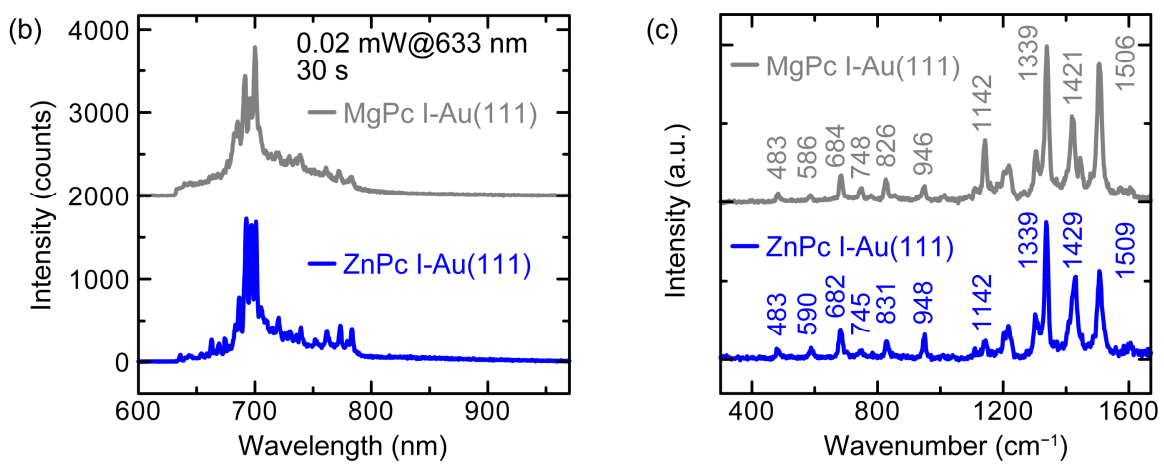

Figure S9. (a) Absorption and emission spectra of $0.01 \mathrm{mM} \mathrm{ZnPc}$ and $\mathrm{MgPc}$ acetone solutions. Emission spectra were taken by the irradiation of the $633 \mathrm{~nm}$ laser $(0.02 \mathrm{~mW})$. (b) Emission spectra of I-Au(111) substrates after the deposition of $\mathrm{ZnPc}$ and $\mathrm{MgPc}$ molecules. The substrates were irradiated by the $633 \mathrm{~nm}$ laser $(0.02 \mathrm{~mW})$. (c) Extracted resonance Raman spectra of $\mathrm{MgPc}$ and $\mathrm{ZnPc}$ molecules on I-Au(111). 


\section{$\underline{\text { References }}$}

S1. Frisch, M. J.; Trucks, G. W.; Schlegel, H. B.; Scuseria, G. E.; Robb, M. A.; Cheeseman, J. R.; Scalmani, G.; Barone, V.; Petersson, G. A.; Nakatsuji, H.; Li, X.; Caricato, M.; Marenich, A. V.; Bloino, J.; Janesko, B. G.; Gomperts, R.; Mennucci, B.; Hratchian, H. P.; Ortiz, J. V.; Izmaylov, A. F.; Sonnenberg, J. L.; Williams-Young, D.; Ding, F.; Lipparini, F.; Egidi, F.; Goings, J.; Peng, B.; Petrone, A.; Henderson, T.; Ranasinghe, D.; Zakrzewski, V. G.; Gao, J.; Rega, N.; Zheng, G.; Liang, W.; Hada, M.; Ehara, M.; Toyota, K.; Fukuda, R.; Hasegawa, J.; Ishida, M.; Nakajima, T.; Honda, Y.; Kitao, O.; Nakai, H.; Vreven, T.; Throssell, K.; Montgomery, J. A., Jr.; Peralta, J. E.; Ogliaro, F.; Bearpark, M. J.; Heyd, J. J.; Brothers, E. N.; Kudin, K. N.; Staroverov, V. N.; Keith, T. A.; Kobayashi, R.; Normand, J.; Raghavachari, K.; Rendell, A. P.; Burant, J. C.; Iyengar, S. S.; Tomasi, J.; Cossi, M.; Millam, J. M.; Klene, M.; Adamo, C.; Cammi, R.; Ochterski, J. W.; Martin, R. L.; Morokuma, K.; Farkas, O.; Foresman, J. B.; Fox, D. J. Gaussian 16 Rev. C.01, Wallingford, CT, 2016.

S2. Tóbik, J.; Tosatti, E., Raman Tensor Calculation for Magnesium Phthalocyanine. Surf. Sci. 2006, 600, 3995-3998.

S3. Barone, V.; Bloino, J.; Biczysko, M. Vibrationally-Resolved Electronic Spectra in GAUSSIAN 09. GAUSSIAN 09 Rev. A02, 1-20, 2009.

S4. Baiardi, A.; Bloino, J.; Barone, V., A General Time-Dependent Route to Resonance-Raman Spectroscopy Including Franck-Condon, Herzberg-Teller and Duschinsky Effects. J. Chem. Phys. 2014, 141, 114108.

S5. Sakakibara, Y.; Bera, R. N.; Mizutani, T.; Ishida, K.; Tokumoto, M.; Tani, T., Photoluminescence Properties of Magnesium, Chloroaluminum, Bromoaluminum, and Metal-Free Phthalocyanine Solid Films. J. Phys. Chem. B 2001, 105, $1547-1553$.

S6. Dennington, R.; Keith, T. A.; Millam, J. M. GaussView Ver. 6, Semichem Inc., Shawnee Mission, KS, 2016. 